\title{
CORRELATES OF BURNOUT AMONG \\ PUBLIC SERVICE LAWYERS
}

Susan E. Jackson

University of Michigan

Jon A. Turner

Arthur P. Brief

New York University

January 1987

\begin{abstract}
Center for Research on Information Systems Information Systems Area

Graduate School of Business Administration

New York University
\end{abstract}

\section{Working Paper Series}

CRIS 非 144

GBA 非87-9

To appear in a forthcoming issue of the Journal of Occupational Behavior. 
- 1 - $\quad$ Lawyer Burnout

\begin{abstract}
Several hypotheses suggested by the theoretical literature on burnout were empirically tested in an attempt to identify the organizational conditions associated with employee burnout. Public service lawyers in the U.S. $(\underline{N}=391)$ completed a survey designed to assess (a) three components of burnout, namely, emotional exhaustion, depersonalization, and feelings of low personal accomplishment; (b) perceptions of several job conditions predicted to be associated these three components of burnout, including workload, role conflict, social support, decision making policies, and autonomy; and (c) organizational commitment. Results indicate that emotional exhaustion is most strongly associated with role conflict and quantitative workload. Feelings of personal accomplishment were associated with supervisory social support and job level. Depersonalization was associated with role conflict and decision making policies. Finally, each burnout component is significantly related to organizational commitment.
\end{abstract}


Correlates of Burnout Among Public Service Lawyers

Researchers interested in studying job stress among human service professionals appear to agree that the concept of burnout expresses well the feelings experienced by some human service employees (Cherniss, 1980; Maslach, 1982). Numerous conceptualizations of the burnout phenomenon have been posited (Meier, 1984; Paine, 1981; Perlman \& Hartman, 1982). Of these, the approach developed by Maslach and her colleagues is one of the most empirically driven. Based upon a sample of 1025 human service professionals employed in a wide variety of occupations, Maslach and Jackson (1981a,b) developed the Maslach Burnout Inventory (MBI) to assess three components of job stress: (1) emotional exhaustion, (2) depersonalization, and (3) feelings of low personal accomplishment at work. Over 10,000 human service professionals in a wide variety of occupations (e.g., nurses, teachers, physicians, police officers, counselors) have completed the MBI, yielding a substantial body of empirical knowledge about the MBI's psychometric properties (see Maslach \& Jackson, 1986).

As measured by the MBI, emotional exhaustion refers to a state of depleted energy which is assumed to be caused by excessive psychological and emotional demands made on people helping people. Use of the word "exhaustion" reflects the assumption that burnout is most relevant for jobholders whose work is very involving, for exhaustion presumes prior states of high arousal. Depersonalization refers to a negative, dehumanizing attitude toward one's clients. This attitude may lead service providers to treat people like objects, as is reflected in the use of object labels rather than personal names when referring to clients. Depersonalizing clients may minimize intense emotional arousal that could interfere with one's functioning, but excessive 
detachment with too little concern is assumed to exist when a staff member reports feelings of callousness and cynicism. The third component measured by the MBI, feelings of low personal accomplishment, was empirically derived (Maslach \& Jackson, 1984) and has received little direct attention. However, the demotivating effects of feelings of inefficacy have been extensively examined in other literatures (Miller \& Norman, 1979). Maslach and Jackson (1981a, b; 1986) reported both convergent and discriminant validity evidence for the MBI. Convergent validity evidence included significant correlations between employees' MBI scores and (a) coworkers' descriptions of employees' reactions to clients, (b) spouses' descriptions of employees' behaviors at home, (c) caseload sizes, and (d) amount of time spent in direct contact with patients. Discriminant validity evidence included low correlations between MBI scores and job dissatisfaction, and nonsignificant correlations with social desirability scores. Reported internal consistency reliabilities for the three MBI scores ranged from .75 to .90 .

The development of reliable, valid measures of burnout was an important first step toward understanding the burnout phenomenon, but much remains to be learned about the antecedents and consequences of burnout. For example, most organizational researchers interested in burnout assume that job conditions are the primary causes of burnout, and that individual characteristics are relatively less important, yet there are few empirical tests of the link between job conditions and burnout. If this assumption is true, an important implication is that burnout can be minimized by creating favorable job conditions.

Theoretical discussions of burnout suggest a variety of job conditions likely to affect experienced burnout. This study tests several hypotheses 
about the relationship of job conditions to burnout. Our hypotheses were developed on the basis of the extant theoretical literature. Below we present these hypotheses and a brief overview of the supporting literature.

Hypothesis 1: Emotional exhaustion is associated with job conditions that directly increase the amount of effort needed to do the job.

This hypothesis follows from the argument that emotional exhaustion results from exerting high levels of effort. Other things being equal, larger caseloads require more effort to perform satisfactorily, thus high levels of emotional exhaustion should occur for human service providers with more, rather than fewer, clients (Turner, 1984). Similarly, high levels of role conflict imply multiple sources of demands, and hence, high levels of effort are necessary to satisfy those demands. Both caseload size and role conflict can be conceptualized as job conditions that demand high effort levels if one is to get the job done.

Large amounts of effort may also be expended in response to perceived productivity norms. Norms governing the "acceptable" level of effort to be expended may arise somewhat independent of actual quantitative workload, but could nevertheless be expected to have a strong influence on the effort levels employees feel obliged to maintain. Finally, work conditions can vary greatly in the extent to which resources, both physical and human, are arranged to facilitate effective performance. When needed resources are either unavailable or difficult to access, added effort must be exerted to be effective. Together, these four conditions should create an environment that demands employees work hard to complete their tasks satisfactorily, and hence emotional exhaustion should be more likely to occur. 
Hypothesis 2: Feelings of low personal accomplishment are associated with job conditions that imply one's efforts are ineffective and/or unappreciated.

The negative effects of feelings of personal inefficacy on motivation and exerted effort is clearly evident from research on learned helplessness, which shows that people exposed to situations in which their efforts repeatedly fail to produce positive results develop symptoms of stress and depression and give up their belief that their actions can make a difference (Abramson, Seligman, \& Teasdale, 1978; Miller \& Norman, 1979). Job conditions likely to convey to employees that their efforts are not being rewarded include failure to receive rewards contingent upon performance, lack of positive, supportive relationships with one's supervisor and colleagues, and an unwillingness on the part of one's supervisor to permit autonomous action, implying that one's past performance has not earned the respect and trust of the supervisor. Assuming members of one's role set are important sources of information about one's own job effectiveness, lack of positive feedback, as reflected by these three variables, should be associated with a personal feeling of failure or lack of accomplishment.

Hypothesis 3: Depersonalization is associated with job conditions that require extensive effort and that lead employees to feel they are embedded in an impersonal, dehumanizing system.

This hypothesis follows from Maslach and Jackson's (1984) argument that depersonalization develops as a coping response to work overload, and Savicki and Cooley's (1983) observation that rigid and controlling administrative practices can invoke depersonalization. The specific job experiences that reflect these conditions are quantitative work load, role conflict, pressures to produce, and lack of participation in decision making. We have included nonparticipatory decision making as a predictor of 
depersonalization based on the assumption that employees will resort to mechanizing their relationships with others when conditions become sufficiently uncontrollable that the environment is perceived as unchangeable. Nonparticipatory decision making is assumed to imply an uncontrollable envi ronment.

Hypothesis 4: Experienced burnout is associated with low organizational commitment.

Most conceptualizations of burnout assume that the typical novice in a human service occupation enters the workforce with a high level of commitment to the job. Indeed, the burnout paradigm assumes that fulfillment of higher order psychological needs is among the primary functions of work for human service professionals. This perspective, represented in the writings of Maslow (1954), Argyris (1957), and others suggests that negative affective reactions to a job cause a desire to leave that job in anticipation of finding an alternative job that will satisfy psychological needs.

Contemporary models of turnover inform us that the process through which desiring to leave a job is translated into actually leaving is complex and includes many intermediate linkages (Mobley, 1982; Steers \& Mowday, 1981), but lower organizational commitment should occur relatively early in the chain of events that eventually leads to turnover. Thus, for burnout to be implicated as a trigger for job turnover, it should be associated with a precursor of turnover, namely organizational commitment.

The present study tests these hypotheses using a sample of public service lawyers. Maslach \& Jackson (1978) argued that public service lawyers may be particularly likely to experience feelings of emotional exhaustion, depersonalization, and low personal accomplishment, because many of the job conditions assumed to contribute to burnout characterize their jobs. Yet this occupational group has received little attention from empirical researchers. 


\section{Method}

\section{Participants and Procedures}

Data were collected in a large agency engaged in the delivery of legal services. The agency had several geographically dispersed offices, organized around legal specialties. As part of an organizational diagnosis, questionnaires were distributed to all employees of the agency through its internal mail system and were returned to the researchers via the U.S. Postal Service. Usable responses were received voluntarily from 391 lawyers representing a response rate of approximately 50\%. Questionnaires were designed to guarantee anonymity. At the agency's request, the only background information gathered about each respondent was (a) whether he or she was a lawyer, (b) whether he or she was a supervisor, (c) office location, and (d) area of legal specialization. Judging from these descriptive data, our sample was representative of the organization's employee population.

Measures

Burnout components. Emotional exhaustion ( 9 items), depersonalization (5 items), and feelings of personal accomplishment ( 8 items) were assessed using the Maslach Burnout Inventory (Maslach \& Jackson, 1981b). The original MBI is designed to assess both frequency and intensity of feelings. These two dimensions have since been shown to be quite strongly correlated (Maslach \& Jackson, 1986). In the present study, only intensity of feelings were assessed.

Job Conditions: Quantitative work load was assessed by a four-item scale developed by Caplan, Cobb, French, Van Harrison, and Pinneau (1975). Role conflict was measured by Rizzo, House, and Lirtzman's (1970) eight-item scale, whose psychometric properties have been favorably assessed (Schuler, 
Aldag, \& Brief, 1977; House, Schuler, \& Levanoni, 1983). Autonomy was assessed using the 6-item index developed by Sims, Szilagyi, and Keller, (1976). Organizational commitment was assessed using Porter and Smith's (1970) index. The construct validity of this index was demonstrated by Mowday, Steers, and Porter (1979). All other job conditions (i.e., pressure to produce, decision making policy, performance-reward relationship, social support from supervisor, arrangement of people ande equipment, and social support from co-workers) were assessed using Newman's (1977) Perceived Work Environment survey. ${ }^{1}$

\section{Results}

Table 1 displays the means, standard deviations, internal consistency reliability estimates, and intercorrelations for all variables. Table 2 presents results from analyses conducted to test hypotheses 1 through 3 . Hypotheses 1 through 3 were tested using hierarchical multiple regression analysis of sets (Cohen \& Cohen, 1975). One equation was computed for each hypothesis, as follows: Job conditions predicted to be most strongly associated with the component under investigation were entered on the first step. On the second step, all other job conditions that had been assessed were entered. Finally, on the third step, job level (supervisor or not a supervisor) was entered. For each hypothesis, empirical support is shown when a significant amount of variance in the dependent variable is explained by the first set of predictors and nonsignificant amounts of variance are explained by the second and third sets of predictors. Empirical support is also shown by the pattern of beta weights in the full regression equation. Significant beta weights should be found for variables entered in the first set of predictors and nonsignificant beta's should be found for variables entered in the second and third sets. 
Tables 1 and 2

Hypothes is 1

Hypothesis 1 predicted that the job conditions most predictive of emotional exhaustion would be conditions that increase the amount of effort needed to do the job. Table 2 shows that the four indices of effort needed, entered as the first set of predictors, explained $14 \%$ of the variance in emotional exhaustion, $\underline{F}(4,386)=17.12, \underline{P}<.05$. Contrary to our predictions, adding the remaining job conditions to the regression equation increased the amount of variance explained by a statistically significant, though relatively small, amount. Inspection of the beta weights for the variables entered as sets 2 and 3 reveals that none is significant. Only quantitative load and role conflict, entered as predictors in the first set, had significant beta values in the full regression equation. Thus, our results partially support Hypothesis 1 .

\section{Hypothesis 2}

Hypothesis 2 predicted that the job conditions most predictive of personal accomplishment would be conditions that imply one's efforts are ineffective and/or unappreciated. Table 2 shows that, contrary to our hypothesis, the four indices entered as the first set of predictors did not explain a significant amount of variance in feelings of personal accomplishment, $\underline{\mathrm{F}}(4,386)=2.33$, ns. However, the beta weight for one variable in this first set of predictors, namely supervisor support, was significant in the full regression equation, providing only very limited support for Hypothesis 2. Other than support from supervisor, the only variable with a significant beta weight in the full regression equation was 
job leve1; lawyers in supervisory positions reported higher feelings of personal accomplishment.

Hypothesis 3

Hypothesis 3 predicted that the job conditions most predictive of depersonalization of one's clients would be conditions that imply intensive effort is needed to do the job and that the embedding system is dehumanizing. Table 2 shows support for this hypothesis. The five predictors entered as the first set explained a significant proportion of variance in depersonalization, $\underline{F}(5,381)=7.15, \underline{p}<.05$. Of these five predicters, two had significant beta weights in the full regression equation, namely, role conflict and decision making policies. Although the remaining job conditions added to the regression equation significantly increased the amount of variance explained, inspection of the beta weights for the variables entered in sets 2 and 3 reveals none is significant.

Hypothesis 4

To test hypothesis 4 , organizational commitment was regressed onto the three burnout components, yielding a significant multiple correlation coefficient, $\underline{R}(3,383)=.51, \underline{\mathrm{p}}<.001$. Inspection of the beta weights revealed that all three burnout components explain significant variance in organizational commitment, as predicted (see Table 3 ).

Table 3 About Here

\section{Discussion}

Overall, the results of our analyses partially support our hypotheses about the job conditions associated with burnout. As predicted, different job 
conditions were associated with the three burnout components. Specifically, emotional exhaustion was most strongly associated with perceived quantity of work load and role conflict. Feelings of personal accomplishment were most associated with supervisor's supportive behaviors. Depersonalization was most strongly associated with role conflict and lack of participation in decision making. In addition, although we had not formulated an hypothesis relating job level to burnout, we found that lawyers in supervisory jobs reported significantly higher levels of burnout for all three components, compared to lawyers in nonsupervisory positions. This finding suggests that there are some facets of supervisory work, not captured by the conditions investigated here, which require isolation. Speculatively, these unidentified, problematic conditions of supervisory work might include the activities demanded of a person who finds him/herself managing employees experiencing burnout. That is, burnout among those who supervise human service professionals may be partly attributable to the burnout of their subordinates.

Clearly the cross-sectional design of this study and our reliance on self-report measures prohibit us from drawing conclusions about causal relationships. Indeed, it is entirely possible that burnout causes negative perceptions about one's job, and that factors other than the job conditions we assessed actually cause burnout. Nevertheless, our findings support developing theory about the social and psychological antecedents of the burnout phenomenon. However, the amount of variance explained by the job conditions we measured is relatively low for the three burnout components; it ranges from as little as $4 \%$ for personal accomplishment to $22 \%$ for emotional exhaustion. This is particularly disheartening given that some covariation between variables is likely due to common method bias. 
In addition, while our predictions about the correlates of burnout were supported by regression analyses of sets of conceptually related variables, the unique contributions of specific job conditions hypothesized to be important were often nonsignificant (see Table 2). Taken together, these results indicate that new theorizing about the burnout phenomenon is needed, as are continuing empirical tests of existing theory. New theorizing may benefit from Lazarus and his associates' cognitive-phenomenological theory of stress and coping (e.g., Lazarus and Folkman, 1984) which dictates that distress (e.g., burnout) can best be understood by attending to how presumably stressful conditions are primarily appraised, how coping resources are assessed, and how people, in fact, cope. Burnout researchers have ignored these processes.

Future empirical research may benefit from the use of occupationally heterogeneous populations. In most empirical studies of burnout, the participants are selected from a single occupational group, (e.g., teachers, nurses, police). A benefit of this approach is that measures can be tailored to the occupation. But a potential shortcoming fo this research strategy is restriction in the range of scores obtained, which in turn may attenuate the correlations found. Future research also needs to move beyond the use of cross-sectional, self-report designs, lest the literature on burnout become as susceptible to criticism as the literature on job stress in general (Kasl, 1978). Happily at least two relatively rigorous studies (one using a longtitudinal design and one using behavioral observations by spouses) have found support for hypotheses about the antecedents and consequences of burnout (Jackson \& Maslach, 1982; Jackson, Schwab, \& Schuler, 1986).

Compared to our results about the possible antecedents of burnout, our results regarding a predicted consequence of burnout, namely lowered 
organizational commitment, were more supportive, although again causal

statements are premature. It is especially noteworthy that each component of burnout explained some unique variation in organizational commitment, for as Table 1 reveals, two of the three burnout components (emotional exhaustion and depersonalization) are themselves correlated.

In conclusion, it seems appropriate to address the possible contextual and practical implications of our findings. This study was conducted in an organization whose members are engaged in public service law, that is, providing legal services to the poor. The results indicate that those lawyers experiencing burnout are less committed to the organization; they report a lower identification with the organization's goals and less willingness to exert effort to achieve those goals. Thus, employee burnout may have serious negative consequences for the people who are to be served by the organization as well as for the employees. Documenting empirically the effects of burnout on the clients of public service employees is an important goal for future research, for without such documentation it may be difficult to convince organizations of the importance of changing any job conditions found to be associated with burnout. 


\section{Footnotes}

${ }^{1}$ Newman's (1977) labels for the measures of social support from supervisor and coworkers are supervisory style and co-worker relations, respectively. 


\section{References}

Abrams on, L. Y., Seligman, M. E. P., \& Teasdale, J. D. (1978). Learned

Helplessness in Humans: Critique and Reformulation. Journal of Abnormal Psychology, 87, 49-74.

Argyris, C. (1957). Personality and Organization. New York: Harper.

Caplan, R. D., Cobb, S., French, J. R. P., Jr., Harrison, R. V., \& Pinneau, S.

R., Jr. (1975). Job Demands and Worker Health. National Institute for

Occupations Safety and Health, Washington, DC.

Cherniss, C. (1980). Staff Burnout: Job Stress in the Human Service.

Beverly Hills: Sage.

Glass, D. C (1977). Behavior Patterns, Stress, and Coronary Disease.

House, R. J., Schuler, R. S., and Levanoni, E. (1983). Role Conflict and

Ambiguity Scales: Reality or Artifacts? Journal of Applied Psychology,

$\underline{68}, 334-337$.

Jackson, S. E., Schwab, R. L., \& Schuler, R. S. (1986). Toward an

Understanding of the Burnout Phenomenon. Journal of Applied Psychology,

71, (4), in press.

Kas1, S. V. (1978). Epidemiological Contributions to the Study of Work

Stress. In C. L. Cooper and R. Payne (Eds.), Stress at Work. Chichester:

John Wiley \& Sons, 1978.

Kobasa, S. C. (1979). Stressful Life Events, Personality, and Health: An

Inquiry Into Hardiness. Journal of Personality and Social Psychology, $\underline{37}$,

1-11.

Lazarus, R. S. and Folkman, S. (1984). Stress, Appraisal, and Coping. New

York: Springer Publishing.

Maslach, C., (1982). Burnout: The Cost of Caring. Englewood Cliffs, NJ:

Prentice-Hall. 
Maslach, C., \& Jackson, S. E. (1978). Lawyer Burnout, Barrister, $\underline{5}$, (2), 8, 52-54.

Maslach, C., \& Jackson, S. E. (1981a). The Maslach Burnout Inventory,

(Research Edition). Palo Alto, CA: Consulting Psychologists Press.

Maslach, C., \& Jackson, S. E. (1984). Burnout in Organizational Settings. In

S. Oskamp (ed.), Applied Social Psychology Annual: Vol. 5: Applications

in Organizational Settings, (pp. 133-154). Beverly Hills, CA: Sage

Publications.

Maslach, C., \& Jackson, S. E. (1986). Maslach Burnout Inventory, Second

Edition. Palo Alto, CA: Consulting Psychologists Press.

Maslow, A. H. (1954). Motivation and Personality. New York: Harper \& Row.

Meier, S. T (1983). Toward a Theory of burnout. Human Relations, $\underline{36}$, 899-

910.

Miller, I. W., \& Norman, W. H. (1979). Learned Helplessness in Humans: A

Review and Attribution Theory Model. Psychological Bulletin, 86, 93-118.

Mobley, W. H., Griffeth, R. W., Hand, H. H., \& Meglino, B. M. (1979). Revi ew

and Conceptual Analysis of the Employee Turnover Process. Psychological

Bulletin, $86,493-522$.

Newman, J. E. (1977). Development of a Measure of Perceived Work Environment.

Academy of Management Journal, 14, 371-397.

Paine, W. S. (ed.) (1981). Proceedings of the First National Conference on

Burnout. Darby, PA: Gwynedd Mercy College/Mercy Catholic Medical Center.

Perlman, B., \& Hartman, E. A. (1982). Burnout: Summary and Future Research.

Human Relations, 35 , 283-305.

Porter, L. W., and Smith, F. J. (197). The Etiology of Organizational

Commitment. Unpublished paper, University of California at Irvine. 
Rizzo, J. R., House, R. J., \& Lirtzman, S. I. (1970). Role Conflict and Ambiguity in Complex Organizations. Administrative Science Quarterly, $\underline{15}$, 150-163.

Savicki, V., \& Cooley, E. (1983, April). The Relationship of Work Environment and Client Contact to Burnout in Mental Health Professionals. Paper presented at the meeting of the American Psychological Association, San Francisco, CA.

Schuler, R. S., Aldag, R. J., and Brief, A. P. (1977). Role Conflict and Ambiguity: A Scale Analysis. Organizational Behavior and Human Performance, 20, 111-128.

Sims, H. P., Szilagyi, A. D., and Keller, R. T. (1976). The Measurement of Job Characteristics. Academy of Management Journa1, 19, 195-212.

Steers, R. M., \& Mowday, R. T. (1981). Employee Turnover and Post-Decision Accommodation Processes. In L. L. Cummings \& B. M. Staw (eds.), Research in Organizational Behavior: Vol. 3, (pp. 235-281). Greenwich, CT: JAI Press.

Turner, J.A. (1984). Computer-mediated Work: The Interplay Between Technology and Structured Jobs. Communications of the ACM, 27 (12), 12101217. 


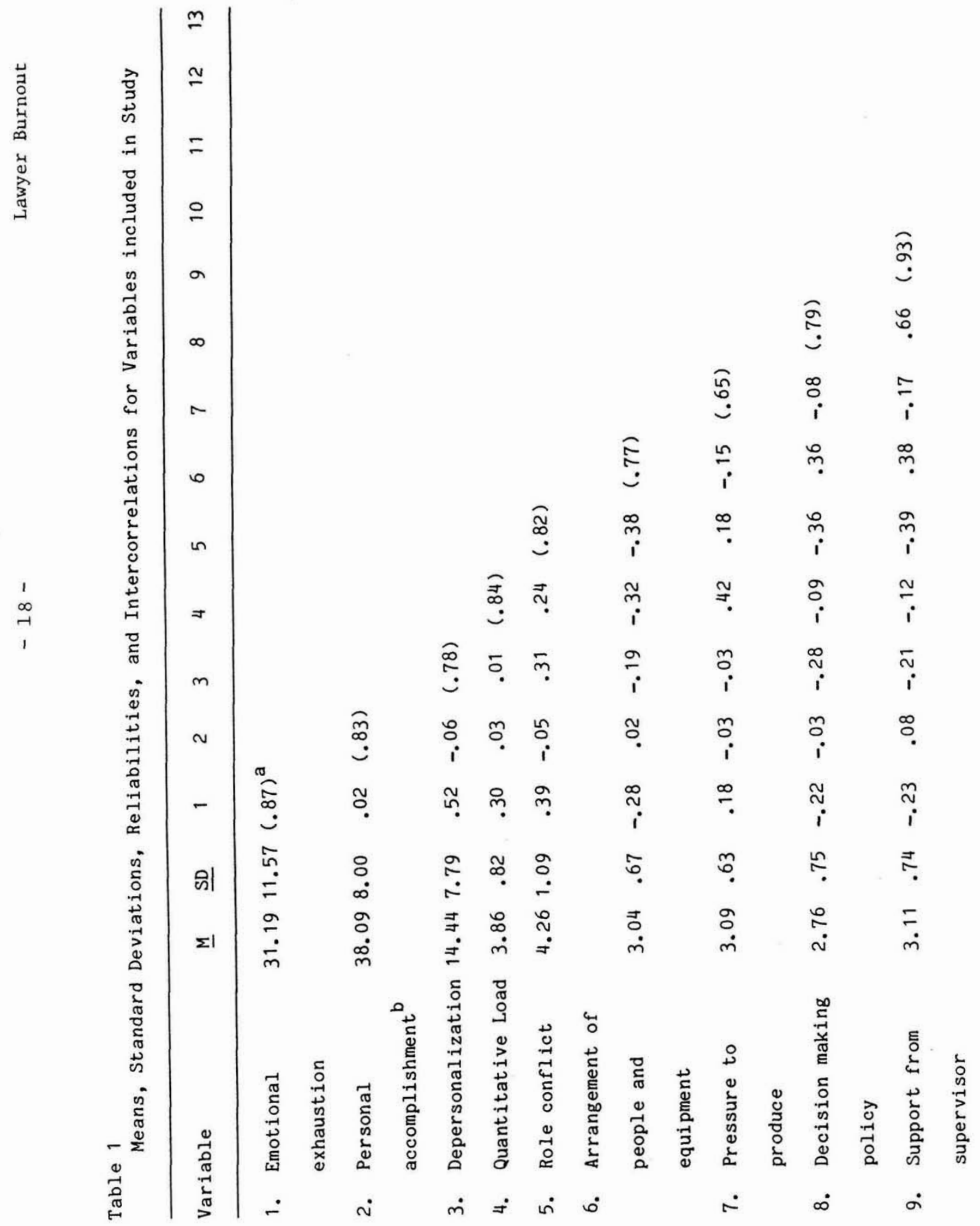




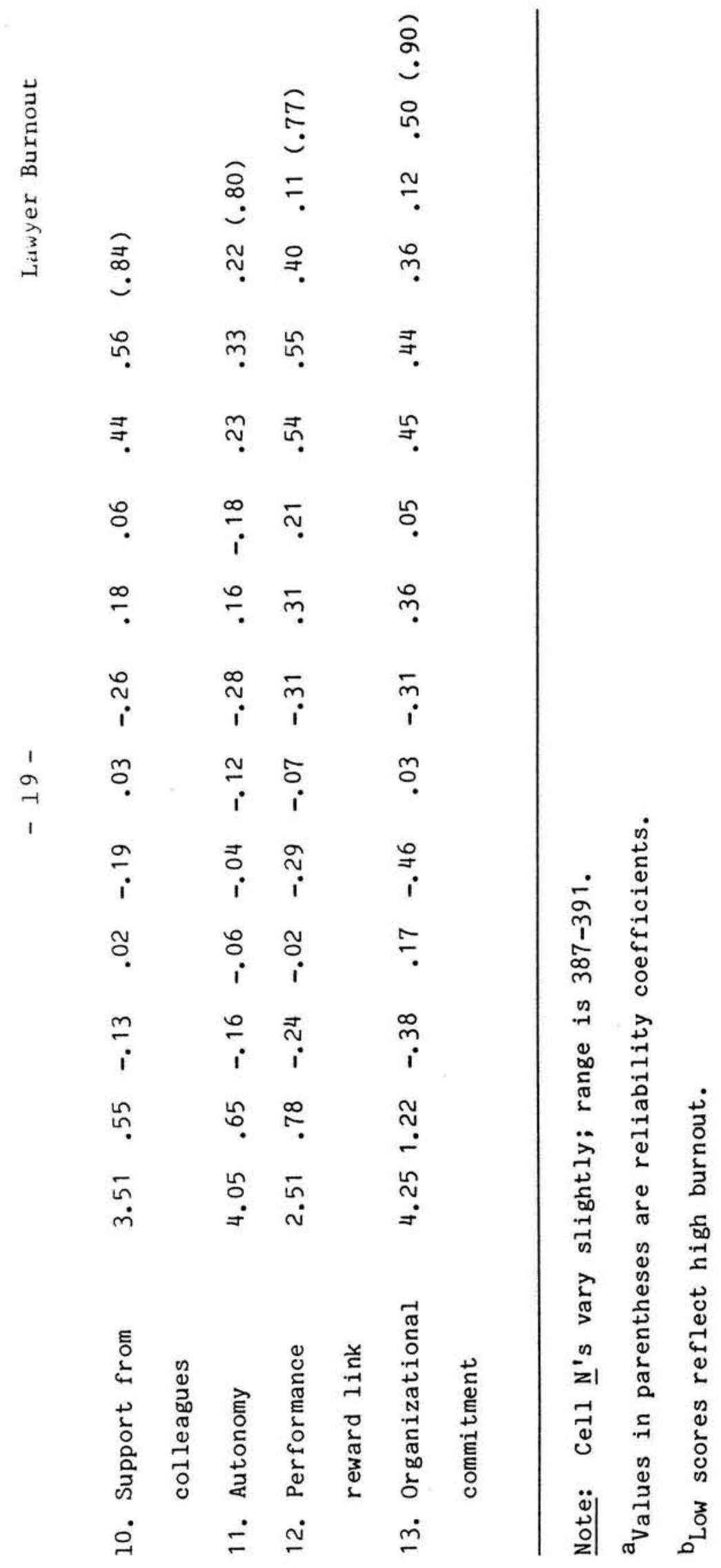


Table 2

Regression Results Showing Relationships of Burnout Components

to Perceived Job Conditions

Variables in Regression Equation $\quad R \quad R^{2}$ set $\quad$ Beta $^{a}$

\section{Emotional Exhaustion}

1. Quantitative load

$.17^{*}$

Role conflict

$.28^{*}$

Pressure to produce

.07

Arrangement of people and equipment

$$
-.05
$$

$.14 *$

2. Performance-reward link

$$
-.12
$$

Decision making policy

$-.02$

Support from coworkers

$-.02$

Support from supervisor

.07

Autonomy

$$
-.05
$$

$.06 *$

3. Job level ${ }^{b}$

$.03^{*}$

.06

\section{$.48 *$}

Personal Accomplishment

1. Performance-reward link

$-.14$

Support from supervisor

Support from colleagues

Autonomy

$-.10$ 
2. Quantitative load

Role conflict

$-.10$

Arrangement of people and equipment .00

Pressure to produce .00

Decision making policy

3. Job level

.02

.01

$-.15^{*}$

$.23^{*}$

Depersonalization

1. Quantitative load

$-.08$

Role conflict

$.27 *$

Pressure to produce

$-.01$

Arrangement of people and equipment

$-.02$

Decision making policy

$-.15^{*}$

$.08^{*}$

2. Performance-reward link

Support from colleagues

$-.08$

Support from supervisor

.14

Autonomy

.05

$.05^{*}$

3. Job level

$.43^{*}$

$.05^{*}$

$.17^{*}$

${ }^{*} \mathrm{p}<.05$

$a_{\text {Beta values are for full equation. }}$

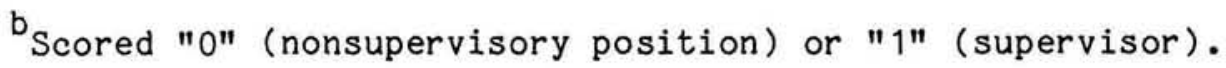

